\title{
IURA NOVIT CURIA EN LA JURISPRUDENCIA CIVIL CHILENA
}

\author{
Iván Hunter Ampuero*
}

\begin{abstract}
RESUMEN
El presente trabajo efectúa un análisis crítico de la principal jurisprudencia nacional que se ba pronunciado en torno a la potestad de los órganos jurisdiccionales para aplicar oficiosamente el Derecho. En su primera parte se explica cómo la distribución de roles procesales ha ido de la mano de una serie de dogmas difícilmente cuestionables y que esa repartición tiene un nítido reflejo en la jurisprudencia nacional. Además se ponen de relieve las principales derivaciones y consecuencias de la concepción de la jurisprudencia que expresa que se debe entregar al juez las cuestiones de Derecho y a las partes los temas fácticos. Por último, a partir de diversos fallos, se explica la necesidad de ir abandonando esta rígida separación ante la necesidad de actuar las garantías procesales como el derecho de defensa.
\end{abstract}

\section{IURA NOVIT CURIA - APLICACIÓN JUDICIAL DEL DERECHO - DERECHO DE DEFENSA}

\section{Iura novit curia in chilean private law jurisprudence}

\begin{abstract}
The present paper carries out a critical analysis of the most relevant Chilean judicial decisions regarding the legal authority of the courts to decide about the legal rules that are applicable to a particular case. In its first part, it is explained how the distribution of procedural roles has responded to a series of hardly questionable dogma, and how its influence on judicial decisions is clear. Also, it deals with the most important consequences of the distinction between matters of law -which determination is assigned to the courts-and factual subject -wbich determination is assigned to the parties. Lastly, based upon diverse rulings, the paper explains the need to leave that rigid separation, in the light of procedural rights as the right of defense.
\end{abstract}

\section{IURA NOVIT CURIA - JUDICIAL APPLICATION OF LAW - RIGHT OF DEFENSE}

\footnotetext{
* Abogado, Magíster y Doctor en Derecho, profesor de Derecho Procesal de la Universidad Austral de Chile, Valdivia, Chile.ivanhunter@uach.cl

Este trabajo fue realizado en el marco y con el financiamiento de la Dirección de Investigación y Desarrollo de la Universidad Austral de Chile (DID), proyecto No 2010-12 (2010-2011), titulado "El rol del juez en el Proyecto de Código Procesal Civil”, del cual el autor de este trabajo es su investigador responsable.

Artículo recibido el 30 de agosto de 2010 y aceptado para su publicación por el Comité Editorial el 27 de octubre de 2010.
} 


\section{INTRODUCCIÓN}

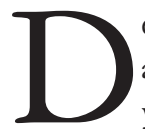
esde hace algún tiempo la doctrina del Derecho Procesal ha renovado una antigua discusión en torno a los roles procesales que deben asumir las partes y el tribunal en el desarrollo dinámico de la jurisdicción. Esta disputa se ha centrado casi exclusivamente en la aportación del material de hecho y la prueba, quedando en el olvido el otro extremo de toda cuestión litigiosa: los materiales normativos o, si se quiere, el Derecho aplicable.

En el derecho nacional, en especial a nivel de la doctrina, el tratamiento que ha recibido la máxima iura novit curia como manifestación del poder del juez para aportar el material jurídico de la controversia ha sido bastante precaria y elemental. Salvo algunas excepciones no hay obras generales o específicas que se detengan a analizar hasta qué punto el órgano jurisdiccional está facultado para desligarse de los fundamentos jurídicos de una pretensión, y qué consecuencias trae esa desvinculación en caso de aceptarse. Más concretamente, si puede el juez apartarse de la calificación jurídica propuesta en una demanda y acoger una pretensión en base a una calificación diversa, autónoma y definida por el órgano jurisdiccional.

En el derecho comparado, especialmente en los ordenamientos donde se han promovido en las últimas décadas reformas al proceso civil, han surgido algunas aproximaciones doctrinales acerca de la correcta inteligencia del iura novit curia desde su aplicación judicial, dando un especial énfasis a su actuación en armonía con los derechos fundamentales del justiciable. Con todo, se trata de un problema que desde un punto de vista más general está relacionado con la repartición de los roles procesales, y los poderes que se le van a asignar al juez.

Las líneas que siguen intentan dar cuenta de tres cuestiones: en primer lugar describir, breve y sumariamente, cómo la disputa acerca del reparto de tareas en el ámbito de la aplicación del Derecho huye de las discusiones generales sobre la función del proceso civil, y se encaja en la aceptación de ciertos dogmas difícilmente cuestionables en el sistema jurídico. Luego, en segundo lugar, intentaré probar cómo esa visión del papel del juez en el ordenamiento está y ha estado presente en nuestra jurisprudencia nacional y las consecuencias para el proceso civil. Esta indagación se centrará, esencialmente, en un estudio jurisprudencial. En tercer lugar, pretendo analizar los problemas que puede llevar aceptar un poder amplio de los jueces en materia de aplicación de las normas jurídicas, en especial, con el derecho de defensa. Para finalizar quisiera ofrecer una interpretación que permita hacer coherente los postulados sustentados hasta el momento por la jurisprudencia con el debido respeto de los derechos de los justiciables, teniendo especial referencia las disposiciones del actual Código de Procedimiento Civil (en adelante CPC). 


\section{LOS DIVERSOS SIGNIFICADOS DEL IURA NOVIT CURIA Y LA DISTRIBUCIÓN DE TAREAS PROCESALES}

Una de las disputas insolubles en la ciencia procesal es la determinación de los papeles que deben desempeñar jueces y partes en el proceso civil. En el ámbito de la doctrina la controversia está empapada de las convicciones acerca de la función del proceso civil en un Estado de Derecho. Así, una postura que entienda que el proceso civil está destinado a lograr la paz social tenderá a excluir los poderes del juez en el ámbito de la aplicación del Derecho. Esta posición es propia del modelo de Estado liberal del siglo XIX, en que la justicia de una decisión supuso equilibrio entre dos fuerzas iguales, similar al funcionamiento del mercado. El Estado asumía un rol pasivo, debiendo constatar si los hechos probados concordaban con la institución jurídica invocada por el actor y que autorizaba el efecto jurídico pretendido. Por el contrario, una postura que vea al proceso civil como una forma de tutela de los derechos de los ciudadanos tenderá a crear herramientas para hacer efectivo ese mecanismo de tutela, aumentando las potestades del órgano jurisdiccional en orden a la aplicación oficiosa del Derecho, autorizándolo a acoger una pretensión con arreglo a fundamentos jurídicos diversos a los sostenidos por las partes.

Esta forma de enfrentar la disputa acerca de los papeles procesales no ha sido la regla general cuando se trata de abordar la libertad por parte del órgano jurisdiccional en la utilización de los materiales jurídicos ${ }^{1}$. El tratamiento de la máxima iura novit curia ha estado estrechamente vinculado a una serie de dogmas que parecen difíciles de cuestionar. El primero de estos dogmas, quizá el más poderoso y significativo, es aquel que entiende al juez como un conocedor del Derecho, es decir, la presunción de que el juez conoce íntegramente la existencia y significados de los textos normativos. Esta circunstancia, en principio, eximiría a las partes de la labor de alegar y probar los elementos jurídicos de una pretensión, junto con liberar al juez de las alegaciones jurídicas que las partes aducen para fundamentarlas ${ }^{2}$. El otro dogma -que poco interesa para este trabajo- es entender a esta máxima como un principio normativo, por el cual los tribunales y jueces deben aplicar, únicamente, el Derecho.

${ }^{1}$ Desde una primera aproximación, como afirma Damaska, puede resultar indiferente al modelo o concepción de proceso (como resolución de conflictos o implementación de políticas) la determinación de a quién le corresponde definir los parámetros legales aplicables a la disputa, puesto que siempre sería responsabilidad del tribunal. Sin embargo -continua el autor-, esta impresión inicial no es tal, ya que mientras más apoyo encuentre el tribunal en las razones jurídicas sustentadas por las partes para definir la cuestión controvertida, ese proceso se acercará en mayor grado a un ideal de resolución de conflictos. El juez decide dentro de los límites jurídicos estipulados por las partes. Por el contrario, una aplicación de la máxima da mibi factum, dabo tibi ius (denme los hechos y yo, el juez, les daré el derecho) parece más cercana a un proceso destinado a implementar políticas estatales, cuestión que permite justificar que el tribunal pueda sentenciar un caso conforme a una teoría jurídica no planteada por las partes. Cfr., Damaska, M., Las caras de la justicia y del poder del Estado. Análisis comparado del proceso legal, Editorial Jurídica de Chile, Santiago, 2000 , p. 197 a 200.

${ }^{2}$ Vid., Ezquiaga, F., Iura novit curia y aplicación judicial del derecho, Editorial Lex Nova, Valladolid, 2008, p. 18. 
Ambas ideas están poderosamente ancladas en una determinada función ideológica del sistema jurídico, en virtud de la cual los jueces, al conocer íntegramente el ordenamiento, se limitarían a aplicar las normas jurídicas vigentes que proporcionan otros órganos del Estado, sin ningún poder creativo ${ }^{3}$. Se trataría, al igual que el postulado del legislador racional, de un principio-construcción esencial para el funcionamiento de todo sistema jurídico ${ }^{4}$. Ningún ordenamiento podría funcionar sin suponer que los jueces conocen y describen las decisiones políticas de otros órganos cuando solucionan los conflictos jurídicos.

Si se asume como válida esta presunción de conocimiento del Derecho por parte del juez, será fácil comprender que la distribución de roles procesales estará fuertemente influenciada por esa proximidad a los materiales jurídicos. En consecuencia, la tarea de las partes sería simplemente la de aportar los materiales fácticos y la prueba. En estos aspectos, son las partes las que están en una situación de proximidad, por ende, pueden cumplir de manera más eficiente esas tareas. Los ciudadanos no tendrían ningún tipo de función en la determinación de los elementos normativos de la litis, y será el juez quien decida cuáles son las reglas jurídicas que amparan o desestiman la petición de tutela del justiciable.

El escenario descrito no es sino un breve esquema de una temática bastante más compleja. Ni el juez conoce todo el Derecho de un ordenamiento ni las partes dejan de asumir un papel relevante en la definición de qué materiales normativos pueden servir para resolver el conflicto a su favor. Tampoco es verdadero que el juez esté completamente alejado a la introducción de algún elemento fáctico, como suelen hacerlo a través de los denominados hechos secundarios 5 .

Por otro lado, este poder del juzgador para aplicar el Derecho tampoco es absoluto. Está sujeto a una serie de limitaciones que, al menos a nivel de la jurisprudencia nacional, parecen no estar tan asumidas. El derecho de defensa de las partes entendido como la posibilidad de contradecir e influir en la decisión puede presentarse como límite a esa libertad del juez. En este sentido, no puede pretenderse que el juez asuma una posición jurídica innovadora frente a los hechos, sin que haya dado a las partes la posibilidad de discutir esa nueva calificación. Tampoco le sería lícito modificar la calificación jurídica contenida en una demanda si con ello vulnera el principio dispositivo y afecta la causa y objeto pedido.

Todos estos aspectos pretendo enfrentar en las páginas que siguen, teniendo como referencia preferente la jurisprudencia de nuestros Tribunales de Justicia.

${ }^{3}$ Ibid., p. 19.

${ }^{4}$ Como explica Ezquiaga, haciendo referencia a la importancia capital de esta máxima en el funcionamiento del sistema jurídico, se trataría de una "elaboración de la ciencia jurídica que sistematiza el ordenamiento jurídico, articula las funciones legislativa y jurisdiccional y se configura como un armazón o estructura que sostiene toda la organización jurídica”. Ibídem.

5 Taruffo, M., La prueba de los hechos, Editorial Trotta, Madrid, 2002, p. 120. 


\section{APLiCACión JUdicial DEL DERECHO, DISTRIBUCIÓN DE ROLES Y LA JURISPRUDENCIA}

La jurisprudencia nacional desde muy temprano fue reconociendo una determinada distribución de roles procesales entre las partes y el juez. De particular relevancia por su claridad y sencillez es una sentencia de la Corte Suprema, de 6 de mayo de 1964, en la cual se deja establecido que "en materia civil los jueces tienen únicamente iniciativa en la aplicación de la ley; y las partes de allegar los hechos en que se basan las acciones y excepciones deducidas. Los jueces de derecho, entonces, tienen el deber inexcusable de aplicar a los hechos invocados y probados los preceptos legales pertinentes, aun cuando no los aduzcan las partes" 6 .

Así entonces es posible advertir que la jurisprudencia sigue aquella tendencia casi universal de radicar en las partes las tareas de alegar los hechos jurídicamente relevantes y proponer los medios de prueba para acreditar la verdad de sus afirmaciones. En esta misión los litigantes tienen un papel relevante por medio de la acción y excepción que son los momentos donde deben introducirse los hechos.

Por el contrario, la jurisprudencia reconoce en el tribunal una función activa en la aplicación de la ley al caso concreto, llegando incluso a restar toda participación de las partes en esa misión. Así lo quiere dar a entender la Corte Suprema, en sentencia de 24 de marzo de 1955, cuando afirma que "es a los tribunales y no a las partes a quienes corresponde aplicar la ley pertinente en la resolución de los asuntos litigiosos" 7 . En este sentido, los fundamentos jurídicos en que se apoya una pretensión y que son una exigencia legal contenida en el Art. 254 N 4 del CPC, no serían vinculantes para el tribunal, teniendo por finalidad -únicamente-proponer las normas legales que pueden favorecerle a quien invoca un derecho amagado ${ }^{8}$. Los jueces al tener la indiscutida libertad para utilizar el Derecho que estimen pertinente a la relación controvertida, podrían acoger o

${ }^{6}$ C. Suprema, 6 de mayo de 1964, R.D.J., t. 61, sec. 1a, p. 81. En similar sentido: C. Suprema, 25 de julio de 1958, R.D.J., t. 55, sec. $1^{\text {a }}$, p. 188; C. Concepción, 29 de abril de 1963, R.D.J., t. 60, sec. $2^{\text {a }}$, p. 49; C. Corte, 25 de noviembre de 1963, R.D.J., t. 60, sec. $1^{\text {a }}$, p. 356; C. Suprema, 11 de agosto de 1965, R.D.J., t. 62, sec. $1^{\text {a }}$, p. 272 ; C. Suprema, 7 de junio de 1972 , R.D.J., t. 69, sec. 1', p. 75. En otra sentencia de la C. Suprema, de 11 de agosto de 1965, R.D.J., t. 62, sec. $1^{\text {a }}$, p. 272, se elevó esta distribución de tareas procesales al carácter de “axioma jurídico, que como tal no requiere demostración”. En este fallo se da cuenta de la justificación que suele venir precedida a la utilización de materiales jurídicos no invocados por las partes, al extremo de sustentar que la libertad de los jueces en la aplicación del derecho es lo que constituye la esencia de la facultad de juzgar, la que si fuere restringida a las argumentaciones de los litigantes haría ilusoria la justicia.

${ }^{7}$ C. Suprema, 24 de marzo de 1955, R.D.J., t. 52, sec. 1, p. 148. En otra sentencia de 19 de diciembre de 1954, señaló que "el derecho que gobierna la especie litigiosa es la que el juez debe de buscar, aun fuera de las alegaciones de las partes”. C. Suprema, 19 de diciembre de 1955, R.D.J., t. 52, sec. 1ª, p. 444. Otro fallo de la Corte Suprema, de 25 de noviembre de 1963, fue claro en señalar que "los sentenciadores están llamados fundamentalmente, atendida su misión, a interpretar y aplicar la ley..." C. Suprema, 25 de noviembre de 1963, R.D.J., t. 60., sec. 1ª, p. 356.

${ }^{8}$ Así, C. Santiago, 22 de julio de 1957, R.D.J., t. 54, sec. $2^{\text {a }, ~ p . ~} 43$. 
rechazar la proposición formulada por la parte demandante, y todo tipo de desacuerdo en ese orden de cosas no tendría consecuencia alguna?

Lo anterior, por cierto, no resulta nada novedoso. La fórmula jurisprudencial recoge, consciente o inconscientemente, los grandes lineamientos de la doctrina del Derecho Procesal en orden a las facultades que se le deben asignar a las partes en los litigios civiles, y los poderes del juez en ese mismo ámbito de tutela. La disímil posición con que ambos partícipes del proceso se enfrentan al ordenamiento jurídico genera una serie de repercusiones de índole eminentemente prácticas que se han visto reflejadas con intensidad en la jurisprudencia.

A continuación trataré de dar cuenta de esas repercusiones en el ámbito de la jurisprudencia nacional, que no son más que las consecuencias necesarias de reconocerle al juez un amplio poder en el manejo del Derecho.

\section{Los jueces pueden corregir el error en la cita legal que se formula en la demanda}

El mayor acercamiento del juez a las normas jurídicas ha justificado su tarea activa para enmendar los errores cometidos por el demandante en cuanto a las citas legales contenidas en la demanda. Así el juez se siente desvinculado de las normas jurídicas que el actor estima que fundamentan su derecho deducido en juicio, y por tal motivo puede corregir e incluso ignorar cualquier cita legal que se haya formulado, y que implique asumir una determinada calificación jurídica de esos hechos.

Bajo esta perspectiva se hace especial hincapié en la necesidad de identificar un hecho o conjunto de hechos, más que a una norma jurídica, como elemento identificador de una determinada pretensión. Particularmente relevante es una sentencia de la Corte Suprema de 24 de marzo de 1955, que señaló: "El error en que incurrió la demandante en encuadrar su acción en los términos de los artículos $271 \mathrm{~N}^{\circ} 1$ del Código Civil y $4^{\circ}$ transitorio y no en el $6^{\circ}$ transitorio de ésta, precepto que contempla la mencionada acción, carece de trascendencia para la discusión de la litis, pues la acción judicial queda configurada por la concurrencia de sus elementos integrantes y no por la citas de las leyes que pueda hacer el actor, toda vez que el Código Procesal exige al efecto que la demanda contenga 'la exposición clara de los hechos y fundamentos de derecho en que se apoya'; pero no requiere, de igual manera, que se mencionen determinados preceptos legales, puesto que es a los tribunales y no a las partes a quienes corresponde aplicar la ley pertinente en la resolución de los asuntos litigiosos" ${ }^{10}$.

${ }^{9}$ Así, C. Suprema, 7 de abril de 1981, R.D.J., t. 78, sec. 1a, p. 29, cuando afirma que "los sentenciadores están dotados de la indiscutida libertad para fundar sus fallos en las normas de derecho que estimen procedentes. En consecuencia, el desacuerdo entre las partes y los falladores en lo referente a las citas legales, no hace que la sentencia adolezca del vicio de falta de fundamentación legal".

${ }^{10}$ C. Suprema, 24 de marzo de 1955, R.D.J., t. 52, sec. $1^{\text {a }}$, p. 148. Así también, en forma clara y categórica, se pronunció la Corte de La Serena, al indicar "la cita equivocada que haga el actor de disposiciones legales no altera lo sustancial de la demanda ni la fisonomía de la acción, error que no obliga al juez de la causa, pues es éste a quien le corresponde aplicar independientemente el derecho...”. C. La Serena, 19 de octubre de 1953, R.D.J., t. 52, sec. 1ª, p. 81. Así también: C. Suprema, 29 de abril de 1954, R.D.J., t. 
Los errores en que haya incurrido el actor al momento de plantear su pretensión son irrelevantes, desde que la fundamentación jurídica que debe contener la demanda cumple una función meramente persuasiva o retórica, que va encaminada a convencer al juez acerca del fundamento de sus peticiones, más no a calificar jurídicamente una pretensión haciéndola vinculante. En este sentido, se ha fallado que "las referencias a disposiciones legales determinadas no son sino alegaciones de los litigantes tendientes a convencer de los fundamentos de sus peticiones, pero no constituyen la acción misma ni sus excepciones" ${ }^{11}$. Los materiales jurídicos invocados por las partes tendrían un carácter discursivo y la disposición legal señalada por el actor no serviría para configurar esa pretensión, ni menos para calificarla jurídicamente ${ }^{12}$.

De esta manera los tribunales tendrían una libertad casi absoluta para desatender las disposiciones legales que operan como fundamento de las pretensiones y decidir el conflicto utilizando otros materiales diversos a los invocados por las partes. Incluso, esta misión lejos de ser una potestad es un verdadero deber que se traduciría en una especial motivación al momento de adoptar la decisión jurisdiccional ${ }^{13}$. Este deber también se ha extendido a las sentencias de segunda instancia, donde se ha exigido del tribunal de alzada determinar en forma precisa y clara el precepto legal aplicable cuando su decisión ha sido revocatorio o modificatorio del fallo de primer grado ${ }^{14}$.

51, sec. $1^{\text {a }}$, p. 95; C. Suprema, 30 de octubre de 1906, R.D.J., t. 6, sec. $1^{\text {a }}$, p. 142; C. Suprema, 2 de mayo de 1910, R.D.J., t. 7, sec. $1^{\text {a }}$, p. 367; C. Suprema, 19 de abril de 1927, R.D.J., t. 25, sec. $1^{\text {a }}$, p. 448 ; C. Suprema, 12 de septiembre de 1931, R.D.J., t. 30, sec. 1a , p. 143; C. Suprema, 14 de abril de 1932, R.D.J., t. 30, sec. $1^{a}$, p. 449; C. Suprema, 6 de agosto de 1992, Rol No 16.065; C. Santiago, 4 de marzo de 2004 , Rol N $\mathrm{N}^{\circ} 7565-2003$.

${ }^{11}$ C. Santiago, 30 de diciembre de 1963 , R.D.J., t. 62, sec. $2^{\text {a }}$, p. 1 (La cursiva es mía).

12 Así la Corte de La Serena decidió que "el juez de la causa debe aplicar el derecho al caso que las partes sometan a su decisión sin que lo obligue la cita errada que haya hecho el actor en su demanda. Es al juez a quien le corresponde aplicar el derecho pudiendo llegar a variar la calificación jurídica de la acción". C. La Serena, 19 de octubre de 1953 , R.D.J., t. 52, sec. $1^{\text {a }}$, p. 81.

${ }^{13}$ Hay varios fallos que han sido particularmente rigurosos con los tribunales al exigir una cita precisa y exacta de las disposiciones legales que deciden un conflicto, cuestión que no han hecho respecto a las partes. Así, por ejemplo, en un antiguo fallo, la Corte Suprema señaló: "La sentencia debe hacer citas concretas y específicas de las disposiciones legales que le sirven de fundamento, y no una cita vaga que no precisa el verdadero principio legal en que se apoya, y por lo tanto, no basta citar un artículo de un Código o cuerpo de leyes en que se contienen disposiciones de naturaleza diversa como base de su resolución”. C. Suprema, 4 de enero de 1906, R.D.J, t. 3, sec. $1^{\text {a }}$, p. 287.

También es posible observar algunas sentencias que han relajado esta exigencia respecto al tribunal, estimando suficientes las citas legales que sirvan para resolver el pleito, aun cuando hayan existido en el fallo citas legales impertinentes (C. Suprema, 5 de octubre de 1932, R.D.J., t. 31, sec. 1a , p. 11), citas incongruentes con los fundamentos y resolución de la sentencia (C. Suprema, 24 de julio de 1913, R.D.J., t. 17 , sec. $1^{\text {a }}$, p. 313 y C. Suprema, 26 de noviembre de 1926 , R.D.J., t. 27 , sec. $1^{\text {a }}$, p. 570 ) e incluso que no haya existido cita legal alguna mientras ésta se desprenda del contexto de los considerandos (C. Suprema, 4 de noviembre de 1919, R.D.J., t. 18, sec. $1^{\text {a }}$, p. 393).

${ }^{14}$ Así, entre otros: C. Suprema, 6 de agosto de 1907, R.D.J., 25, sec. 1ª p. 447; C. Suprema, 13 de diciembre de 1915, R.D.J., t. 13, sec. $1^{\text {a }}$, p. 95; C. Suprema, 7 de marzo de 1928, t. 26, sec. $1^{\text {a }}$, p. 95 y C. Suprema, 28 de mayo de 1913, R.D.J., t. 11, sec. $1^{\text {a }}$, p. 391. 


\section{Los jueces pueden suplir la falta de cita legal de la demanda}

Otra de las consecuencias que se sigue de la proximidad que se le reconoce al juez al Derecho es la posibilidad de suplir la falta de indicación de la norma jurídica que encuadra la acción y excepción. No sólo la errónea calificación jurídica contenida en la demanda queda superada con la posibilidad reconocida al juez para aplicar los materiales jurídicos del caso, sino también la falta o ausencia de esa calificación. Cuando en la pretensión el actor no efectúa una calificación de los hechos que expone, entonces el juez queda autorizado para vincular esos hechos a la norma jurídica que estime correcta y pertinente.

En este sentido, la jurisprudencia ha sostenido de manera uniforme que el hecho de fundar la sentencia en una cita legal no invocada por el demandante no justifica la causal de ultra petita como vicio de casación en la forma. Así, la Corte Suprema, en sentencia de 2 de mayo de 1955, señaló que "no falla ultra petita la sentencia que al hacer la enunciación de las leyes con arreglo a las cuales se pronuncia el fallo, cita algunas no invocadas por el demandante al deducir su acción"15.

No obstante lo anterior, la jurisprudencia tampoco exonera completamente a la parte de su carga de situar la controversia dentro de un contexto necesariamente jurídico, y les exige "señalar los principios o razones jurídicas en que se apoya" ${ }^{16}$, aun cuando esta argumentación sea equívoca o errónea. Esto implica que el tribunal puede y debe suplir ex officio la errónea o imperfecta invocación del material jurídico que hayan efectuado las partes ${ }^{17}$. Este razonamiento es coherente con lo sustentado en otras sentencias. La carga de las partes en el ámbito de la utilización de los materiales jurídicos es mínima. Prácticamente se les exige -en forma exclusiva-, que los hechos afirmados puedan justificar la tutela solicitada.

\section{El juez puede complementar y separarse de la fundamentación jurídica esgrimida por la parte}

El juez en virtud de este poder de apreciar las normas aplicables a la cuestión debatida puede suplir, rectificar o complementar las explicaciones o razonamientos que sustentan las defensas de los litigantes. En otras palabras, puede acoger una pretensión en base a un razonamiento jurídico diverso al expuesto al momento de fundamentar la demanda. Así lo ha dicho la Corte Suprema, en sentencia de 11 de octubre de 1966,

${ }^{15}$ C. Suprema, 2 de mayo de 1955 , R.D.J., t. 52, sec. $1^{\text {a }}$, p. 80, y además: C. Suprema, 9 de diciembre de 1917, R.D.J. t. 18, $2^{a}$ parte, p. 195, y C. Suprema, 22 de julio de 1919, R.D.J., t. 18, $2^{a}$ parte, p. 126. La Corte de Apelaciones de Santiago, citando al efecto algunas sentencias de la Corte Suprema, ha dicho que al juez le corresponde hallar de oficio la norma que corresponda al hecho, sin que ello pueda entenderse como ultra petita. Agrega además que "el tribunal debe calificar las argumentaciones y hechos de acuerdo al Derecho que conoce, y no a cómo sea formulado por las partes”. C. Santiago, 30 de enero de 2007, Rol $\mathrm{N}^{\circ}$ 1241-2006.

${ }^{16}$ C. Valparaíso, 27 de noviembre de 1927, Gaceta Jurídica, 1927, 2º sem., No 151, p. 665 y C. Concepción, 31 de julio de 1953, R.D.J., t. 50, sec. $2^{\text {a }}$, p. 66.

${ }^{17}$ C. Concepción, 19 de junio de 1958 , R.D.J., t. 55, sec. $2^{\text {a }}$, p. 32. 
al expresar que "al apreciar los hechos del pleito los jueces tienen amplia facultad para agregar las explicaciones de las partes, aun las que ellas no han dado y que sirven para esclarecer la cuestión, y no incurren por eso en ultra petita" ${ }^{18}$. Igual de categórico fue otro fallo de la Corte Suprema, de 4 de octubre de 1935, que decidió que "no le está vedado al tribunal sentenciador consignar los razonamientos que crea conducentes siempre que no alteren las acciones y excepciones que se han opuesto en el juicio" ${ }^{19}$. Lo importante es que cuando se acoge una acción o excepción el juez respete aquello que la determina, esto es, la causa de pedir o condición jurídica de las mismas.

En este sentido, la exigencia de congruencia de las resoluciones judiciales no significa que el juez deba plegarse a algunas de las tesis y fundamentos esgrimidos por alguna de las partes. No le está vedado al juez añadir razonamientos diferentes e incluso contradictorios a los sustentados en una demanda. Obviamente, estas nuevas razones deben respetar el fundamento de la pretensión, entendida como aquel conjunto de hechos del cual se desprende la tutela pedida. Además el razonamiento justificativo que haga el juez por muy libre que pueda ser debe desprenderse de la cuestión misma que se debate o de las demás piezas del proceso $^{20}$.

Con esto nuestra jurisprudencia parece reconocer una distinción claramente afianzada en el derecho comparado ${ }^{21}$, entre lo que es fundamento de lo pedido que coincide con la causa de pedir y que viene dado por un conjunto de hechos de los cuales se desprende el beneficio jurídico perseguido, y la fundamentación que se trataría de un ejercicio racional destinado a dar razones para estimar o rechazar la pretensión.

${ }^{18}$ C. Suprema, 11 de octubre de 1966, R.D.J., t. 63, sec. $1^{\text {a }}$, p. 364; C. Suprema, 25 de abril de 1914, R.D.J., t. 16, sec. $1^{\text {a }}$, p. 229; C. Suprema, 27 de abril de 1931, R.D.J, 29, $2^{\text {a }}$ parte, p. 223; C. Suprema, 1 de diciembre de 1931, R.D.J., t. 29, $2^{\text {a }}$ parte, p. 236; C. Suprema, 28 de abril de 1949, R.D.J., t. 49, sec. $1^{\text {a }}$, p. 285; C. Suprema, 22 de septiembre de 1954, R.D.J., t. 51, sec. $1^{\text {a }}$, p. 446; C. Suprema, 29 de octubre de 1956, R.D.J., t. 53, sec. $1^{\text {a }}$, p. 297; C. Suprema, 15 de octubre de 1964, R.D.J., t. 63, sec. $2^{\text {a }}$, p. 10.

${ }^{19}$ C. Suprema, 4 de octubre de 1935 , R.D.J., t. 33, sec. $1^{\text {a }}$, p. 28, y C. Suprema, 29 de octubre de 1931, Gaceta Jurídica, 1931, $2^{\circ}$ sem., N³9, p. 209. Otro grupo de sentencias fueron particularmente claras en reconocer que "los jueces del fondo están autorizados para consignar en sus fallos todos los fundamentos o consideraciones de derecho referentes a la acción ejercitada, aunque las partes no los hubiere tratado”. C. Suprema, 22 de septiembre de 1905, R.D.J., t. 3, sec. 1', p. 125; C. Suprema, 21 de mayo de 1911, R.D.J., t. 10 , sec. $1^{\text {a }}$, p. 571; C. Suprema, 6 de septiembre de 1919, R.D.J., t. 21, sec. $1^{\text {a }}$, p. 74; C. Suprema, 30 de diciembre de 1924, R.D.J., t. 24, sec. $1^{\text {a }}$, p. 455; C. Suprema, 14 de enero de 1928, R.D.J, t. 28, sec. $1^{\text {a }}$, p. 311; C. Suprema, 9 de diciembre de 1929, R.D.J., t. 9, sec. $1^{\text {a }}$, p. 393; C. Suprema, 11 de abril de 1931 , R.D.J., t. 29, sec. $1^{\text {a }}$, p. 267; C. Suprema, 5 de mayo de 1995, Rol No 23386-2004.

${ }^{20}$ Así se dijo, entre otras: C. Suprema, 7 de octubre de 1915, Gaceta Jurídica, 1915, $2^{\circ}$ sem., N ${ }^{\circ} 515$, p. 1347; C. Suprema, 27 de octubre de 1915, Gaceta Jurídica, 1915, $2^{\circ}$ sem., No 535, p. 1401; C. Suprema, 16 de noviembre de 1916, R.D.J., t. 16, sec. 1a, p. 365; C. Suprema, 19 de noviembre de 1917, Gaceta Jurídica, 1917, $2^{\circ}$ sem., N 70, p. 210; C. Suprema, 15 de noviembre de 1924, Gaceta Jurídica, 1924, $2^{\circ}$ sem., $\mathrm{N}^{\circ} 45$, p. 247. También hay sentencias en contrario que estiman válida la decisión jurisdiccional que se pronuncia con fundamentos completamente diferentes a la cuestión debatida. Así, entre otras, C. Suprema, 11 de abril de 1946, R.D.J, t. 43, sec. 1a , p. 421; C. Suprema, 24 de septiembre de 1941, R.D.J., t. 40, sec. $1^{\text {a }}$, p. 54; C. Suprema, 4 de septiembre de 1940, R.D.J., t. 39, sec. ${ }^{\text {a }}$, p. 99; C. Suprema, 24 de diciembre de 1936, R.D.J., t. 36, sec. $1^{\text {a }}$, p. 228.

${ }^{21}$ Vid., De la Oliva Santos, A., El objeto del proceso y la cosa juzgada en el proceso civil, Civitas, Madrid, 2005 , p. 69. 
Así, un fallo de la Corte Santiago, de 8 de julio de 1941, señala que "no se puede confundir lo que el artículos 177 del Código de Procedimiento Civil, define como 'fundamento inmediato del derecho deducido en juicio' con los 'fundamentos de derecho' en que se apoya la demanda. Se trata de cosas distintas; una dice relación con el hecho constitutivo del derecho, que se llama causa de pedir; la otra se refiere a los raciocinios o apreciaciones de índole jurídica que el actor aduce para calificar ese hecho"22.

De esta forma el fundamento de lo solicitado estaría compuesto por un conjunto de hechos de los cuales se desprende lo pedido por el actor o lo resistido por el demandado. Este fundamento coincidiría con la causa de pedir, y en cuanto dato fáctico sería resorte exclusivo de los litigantes alegarlo. Estos hechos que identifican la pretensión se corresponden con aquello que la jurisprudencia denomina indistintamente "hecho jurídico" o "hecho material"23. El tribunal, por su parte, si bien obligado a respetar los hechos, tiene absoluta libertad para justificar jurídicamente su decisión sin necesidad de adherirse a la fundamentación esgrimida por las partes.

\section{Libertad para determinar la procedencia de las acciones y excepciones}

Hay cierto consenso en la jurisprudencia al momento de señalar que el juez tiene el deber de constatar de oficio la concurrencia de todos los elementos que conforman la acción deducida, aun cuando las partes hayan sido pacíficas al momento de determinar su concurrencia. En este sentido, hay diversos fallos de la Corte Suprema que reafirman la atribución privativa de los jueces para apreciar la procedencia de las acciones y excepciones sometidas a su conocimiento y para dar las razones legales para acogerlas o no, aunque no hayan sido alegadas por las partes ${ }^{24}$. De igual forma, la jurisprudencia ha estimado que la posibilidad de actuar de oficio verificando todos los extremos de una pretensión no implica traspasar los límites de lo deducido. Así, la Corte Suprema, en fallo de 10 de julio de 1970, señaló que "no se extiende a puntos no sometidos a su decisión y no incurre por lo tanto en ultra petita, aquel tribunal que sin petición de parte examina la concurrencia de los presupuestos legales para el ejercicio de la acción"25-26.

${ }^{22}$ C. Santiago, 8 de julio de 1941, R.D.J., t. 39, sec. $2^{\text {a }}$, p. 41.

${ }^{23}$ Los fallos que utilizan estas expresiones son abundantes. Así, entre otros: C. Rancagua, 21 de agosto de 2001, Rol N 16485-2000; C. Suprema, 7 de enero de 1994, Rol N 1851-1993; C. Suprema, 6 de agosto de 1992, Rol No 16.065; C. Suprema, 11 de octubre de 1990, Rol No 12473; C. Suprema, 19 de abril de 1988, Rol No 11322, y C. Santiago, 15 de diciembre de 2004, Gaceta Jurídica, 2004, No 294, p. 95.

${ }^{24}$ C. Suprema, 7 de enero de 1914, Gaceta Jurídica, 1914, $1^{\text {er. }}$ sem., N ${ }^{\circ} 13$, p. 35; C. Suprema, 28 de diciembre de 1914, Gaceta Jurídica, 1914, $2^{\circ}$ sem., No 560, p. 1536; C. Suprema, 29 de diciembre de 1917, Gaceta Jurídica, 1917, $2^{\circ}$ sem., N 148, p. 446; C. Suprema, 10 de abril de 1918, Gaceta Jurídica, $1^{\text {er. }}$ sem., No 41, p. 122 y C. Suprema, 27 de abril de 1931, R.D.J., t. 29, sec. $1^{\text {a }}$, p. 223.

${ }^{25}$ C. Suprema, 10 julio de 1970, R.D.J., t. 67, sec. 1a , p. 248. En idéntico sentido: C. Suprema 26 de mayo de 1964, R.D.J., t. 61, sec. $1^{\text {a }}$, p. 125; C. Suprema, 16 de junio de 1964, R.D.J., t. 61, sec. $1^{\text {a }}$, p. 358 ; C. Suprema, 17 de julio de 1964, R.D.J, t. 61, sec. $1^{\text {a }}$, p. 212; C. Suprema, 10 de abril de 1966, R.D.J., t. 63, sec. $1^{\text {a }}$, p. 116; C. Suprema, 8 de junio de 1970, R.D.J., t. 67, sec. $1^{\text {a }}$, p. 187; C. Suprema, 9 de julio de 1970, R.D.J., t. 67, sec. $1^{\text {a }}$, p. 243; C. Suprema, 10 de julio de 1970, R.D.J, t. 67, sec. $1^{\text {a }}$, p. 248, y; C. Santiago, 2 de junio de 2000, Rol N 6.648-1997.

${ }^{26} \mathrm{Si}$ bien las sentencias no lo precisan, podría decirse que los jueces cumplen una doble función en este punto. En primer lugar, verificar la existencia de los hechos, lo que se trata de una tarea eminentemente 
En este aspecto el sentenciador no queda ligado a los términos negativos del debate, esto es, no está en el deber de aceptar como jurídicamente correctos los extremos de la pretensión que las partes no han controvertido. Los puntos jurídicos aceptados por las partes no pueden considerarse puntos pacíficos para el juez, quien tendría siempre el deber de verificarlos ex officio. Así fue especialmente resuelto por la Corte Suprema, en fallo de 2 de septiembre de 1940, donde anuló una sentencia que no se pronunció acerca de la calificación jurídica de un determinado contrato por estar de acuerdo las partes en tal calificación y estimar que se trataba de un punto jurídicamente pacífico ${ }^{27}$. Se puede observar aquí la clara posición que ocupa el juez en relación a los hechos -y que lo diferencia de su posición frente al Derecho-, ya que en tal ámbito no puede desconocer la existencia de un hecho pacífico, y sobre el cual hay acuerdo en su existencia.

Esta libertad puede ser observada como la contrapartida del poder del juez para corregir las imperfecciones en que haya incurrido el litigante al momento de fundamentar jurídicamente sus posiciones. En sencillas palabras, una pretensión jurídicamente mal formulada puede prosperar en la medida que el juez corrige ese defecto en la invocación del material jurídico; por el contrario, una pretensión jurídicamente pacífica (no discutida en el ingrediente jurídico) puede rechazarse si el juez estima que no cumple con el ordenamiento.

\section{La aplicación judicial del derecho es compatible con el principio dispositivo}

La vinculación entre aplicación judicial del Derecho y principio dispositivo había sido desconocida por nuestra jurisprudencia nacional ${ }^{28}$. Los tribunales venían legitimando una determinada visión del principio dispositivo anclado en los ideales liberales del siglo XIX, donde tal máxima era entendida como la adjudicación a las partes del dominio del proceso en sus aspectos formales y de impulso procesal ${ }^{29}$. Obviamente, si

valorativa de la actividad probatoria. En segundo lugar, determinar si esos hechos cuadran en los supuestos de la pretensión deducida, actividad ésta que es jurídica. Es esta última función a la que hago referencia en este punto.

${ }^{27}$ C. Suprema, 2 de septiembre de 1940, R.D.J., t. 38, sec. $1^{\text {a }}$, p. 312.

${ }^{28}$ En el ámbito de la doctrina comparada esta conexión había sido resaltada y discutida. Sólo a modo de ejemplo, puede citarse: Tapia, I., El objeto del proceso. Alegaciones. Sentencia. Cosa juzgada, Editorial La Ley, Madrid, 2000, p. 24; Vallines, E., La preclusión en el proceso civil, Civitas, Madrid, 2004, pp. 210 ss, y Prieto, L., "El cambio del punto de vista jurídico" en Revista de Derecho Procesal, Madrid, 1956, p. 255.

${ }^{29}$ Especialmente relevante es la sentencia de la Corte Suprema de 25 de marzo de 2009, Rol N ${ }^{\circ} 7491$ 2008, que señala: "Considerando Cuarto: Dentro del ámbito procesal, ello trasunta en el efecto del incumplimiento de una determinada actuación o carga dentro de un lapso determinado, lo que presupone que el procedimiento respectivo se erija sobre el principio dispositivo pues sólo así se explica y justifica el deber de las partes de impulsar el mismo". Para un comentario crítico de este fallo puede verse: Hunter, I., “¿Tiene el tribunal algún deber en orden al impulso procesal en el actual proceso civil chileno?", en Revista de Derecho Universidad Austral de Chile Tomo XXI, Vol. 1, 2009, pp. 265 a 274. Otra sentencia de la Corte Suprema de 6 de junio de 2007, Rol N 5702-2005, si bien reconoce que el impulso procesal puede recaer en el tribunal entiende que se trata de una situación que hace expresa excepción al principio dispositivo consagrado en el Art. 10 del Código Orgánico de Tribunales. En otros fallos derechamente se confunde el principio dispositivo con el de pasividad, y se contrapone al de 
el principio dispositivo miraba de manera esencial a las cuestiones procedimentales y no tenía ninguna relación con los bienes tutelados, carecía de toda trascendencia al momento de identificar las normas jurídicas aplicables. En otras palabras, este principio no jugaba ningún papel en la actividad de aplicar las normas jurídicas a los hechos alegados, por la sencilla razón de estar vinculado a otras situaciones del proceso.

Con todo, la relación entre iura novit curia y principio dispositivo fue puesta de manifiesto en un fallo de la Corte de Apelaciones de Santiago, de 9 de octubre de 2001, rol No 5621-1999. En este caso, el demandado había opuesto a la ejecución una excepción de prescripción especial y no la ordinaria, que era la prescripción legalmente procedente. La sentencia reconociendo la plena vigencia de este principio, en cuanto sujeta al juez a los términos de la excepción opuesta, entiende que "el principio dispositivo (...), somete al tribunal a las materias que forman parte del debate, de manera que se vea impedido de tomar la iniciativa respecto de otros temas de aquellos que conforman la causae paetendi y el petitum. Lo anterior no excluye la plena vigencia de aquel otro principio, conocido como iura novit curia, según el cual el basamento jurídico de la decisión queda radicado en el tribunal, el que es libre para fundamentar en derecho. Así las cosas, se tiene que, habiéndose impetrado la prescripción con determinado respaldo y conceptuación jurídicos, la judicatura se pronuncia sobre ella, desestimando aquéllos y otorgando a la resolución una apoyatura que, en cuanto razonamiento vertido de conformidad con el numeral quinto del artículo 170 del Código de Procedimiento Civil, le es soberana”. (Considerando noveno).

Este fallo es fundamental puesto que pone de manifiesto varios extremos del problema. En primer lugar, vincula el principio dispositivo a la causa de pedir y al petitum, esto es, al fundamento del derecho deducido en juicio y al beneficio jurídico que se persigue con la pretensión. Esta relación es exacta. El principio en cuestión impide al juez otorgar una cosa distinta a la pedida, como también cambiar el criterio de relevancia con que los hechos han sido introducidos al proceso. Así entonces se respeta el principio dispositivo cuando el juez, en uso de la libertad que le confiere su posición institucional, da a los hechos la calificación que estima conveniente para conceder el efecto jurídico pretendido por el actor o demandado.

Esto es lo que sucede en este caso. El tribunal no se ve compelido a seguir la tesis jurídica de la demandada que sostenía que la prescripción opuesta era una especial y no ordinaria, puesto que aun modificando esa calificación mantiene la intangibilidad de la excepción. Mientras se mantenga inalterado lo pedido, el juez sería libre para moverse en el ámbito de las normas jurídicas que estime aplicable a los hechos. Lo importante, para esta sentencia, es que todo poder del juez para aplicar el Derecho encuentra como límite infranqueable el petitum. Por el contrario, si el juez determina que los hechos alegados no dan origen a la excepción opuesta (prescripción) sino a otra, entonces no le queda otro camino que rechazarla.

oficialidad (Corte Suprema, 21 de septiembre de 2000, Rol No 3789-2000). Por ende, es posible observar que a nivel de la jurisprudencia no hay claridad de qué es y qué implica el principio dispositivo. 
Llevado este razonamiento al ámbito del actor, entiendo que cuando el ciudadano pretende un efecto jurídico afirma la existencia de unos hechos que integran el presupuesto de la norma que fundamenta y hace posible ese efecto. Si el ordenamiento no permite conceder la tutela en base a los hechos alegados entonces el juez queda inmediatamente restringido en el ámbito de aplicación del Derecho. Por ejemplo, si el actor califica jurídicamente su pretensión como de error esencial estimando que existe un vicio del consentimiento y solicita la nulidad de un contrato, no puede el juez estimar que esos mismos hechos determinan la existencia de un incumplimiento de contrato y resolverlo. La intangibilidad de la petición (respeto por el petitum utilizando los términos de la sentencia) como manifestación del principio dispositivo, sí provoca un efecto delimitador de los materiales jurídicos que se pueden utilizar para conceder la tutela pedida.

Ahora bien, la inalterabilidad de lo pedido no significa que el juez no pueda remediar los errores que cometan las partes al momento de seleccionar la norma aplicable. Es perfectamente posible que los litigantes obtengan una sentencia favorable y al mismo tiempo se equivoquen en invocar el estatuto jurídico que estiman aplicable a su relación jurídica-material. El juez puede remediar ese yerro aplicando las normas jurídicas correctas, pero debe respetar íntegramente lo pedido en la demanda y lo resistido en la contestación. Así lo resolvió de modo expreso una reciente sentencia de la Corte de Apelaciones de Santiago, de 2 de diciembre de 2009, cuando rechaza un recurso de casación en la forma fundado en el vicio de ultra petita, estimando que los tribunales están autorizados "a aplicar una norma jurídica diversa si no se altera con ello la naturaleza de lo demandado"30.

Esos son los límites que impone el principio dispositivo en la utilización de los materiales jurídicos y quedan en cierta forma cubiertos por la prohibición de ultra petita.

Creo que este es el razonamiento que se lee cuando la jurisprudencia admite que "la ultra petita se produce solamente en la parte resolutiva del fallo, por lo que no procede fundar un recurso por esta causal en la circunstancia que en los considerandos se expongan fundamentos discordantes o ajenos a la materia del juicio" ${ }^{31}$. El juez tendría un amplio margen para aplicar los materiales jurídicos que estimen relevantes para los

${ }^{30}$ C. Santiago, 2 de diciembre de 2009, Rol 4247-2008. Cabe precisar, eso sí, que si bien el fallo razona entendiendo que el tribunal puede aplicar una norma jurídica diversa respetando únicamente el objeto pedido, los hechos de este caso muestran más bien que se trata de una situación donde el juez examina de oficio el cumplimiento de todos los presupuestos o requisitos de procedencia de la pretensión interpuesta incluso en algunos extremos que no habían sido objeto de debate.

${ }^{31}$ Sobre esta materia se han pronunciado diversos fallos, y sólo cito los más relevantes: C. Suprema, 9 de diciembre de 1905, R.D.J., t. 3, sec. 1ª, p. 259; C. Suprema, 28 de diciembre de 1914, R.D.J., t. 3, sec. $1^{\text {a }}$, p. 169; C. Suprema, 11 de enero de 1915, R.D.J., t. 12, sec. $1^{\text {a }}$, p. 568; C. Suprema, 15 de abril de 1916, R.D.J., t. 15, sec. $1^{\text {a }}$, p. 473; C. Suprema, 4 de enero de 1917, R.D.J., t. 14, sec. 1'a p. 533 ; C. Suprema, 10 de enero de 1919, R.D.J., t. 19, sec. $1^{\text {a }}$, p. 361; C. Suprema, 3 de marzo de 1921, R.D.J., t. 21, sec. $1^{\text {a }}$, p. 219; C. Suprema, 1 de agosto de 1924, R.D.J., t. 23, $2^{\text {a }}$ parte, p. 454; C. Suprema, 10 de julio de 1925, R.D.J., t. 25, $2^{\text {a }}$ parte, p. 245; C. Suprema, 19 de noviembre de 1927, R.D.J., t. 26, $2^{\text {a }}$ parte, p. 60; C. Suprema, 14 de enero de 1928, R.D.J., t. 28, $2^{\text {a }}$ parte, p. 311; C. Suprema, 11 de abril de 1929, R.D.J., t. 29, $2^{a}$ parte, p. 563; C. Suprema, 28 de julio de 1930, t. 31, $2^{\text {a }}$ parte, p. 551; C. Suprema, 2 de diciembre de 1931, R.D.J., t. 31, $2^{a}$ parte, p. 51, y; C. Suprema, 19 de abril de 1931, t. 29, $2^{\text {a }}$ parte, p. 411. 
hechos planteados, aun cuando no coincidan y sean incluso discordantes con los sustentados por las partes. El único límite es la coherencia que debe existir entre lo pedido y otorgado, es decir, que el juez no puede modificar el beneficio jurídico perseguido con la demanda. De traspasar ese límite la sentencia incurriría en el vicio de ultra petita.

\section{Apreciación Crítica de la JURISPRUdenCia EN MATERIA DE APLICACIÓN EX OFFICIO DEL DERECHO}

\section{La distribución de tareas procesales}

Hay varias cuestiones que llaman poderosamente la atención de los razonamientos jurisprudenciales arriba expuestos y sobre los cuales vale la pena plantear algunas reflexiones. En primer lugar, la adjudicación al juez de un rol preponderante -y hasta a veces monopólico- en la aplicación del Derecho se asienta en dogmas no positivizados o que carecen de todo sustento normativo. El ordenamiento nacional no se preocupa -ni menos el proceso civil- de reconocer expresamente al órgano jurisdiccional un poder amplio para aplicar la norma jurídica al caso concreto, desatendiendo aquella que el actor ha fundado su pretensión. Es más, tampoco hay una norma que autorice al juez a acoger una pretensión en base a una calificación diversa a la propuesta por el actor, no obstante, los tribunales suelen hacerlo con bastante frecuencia ${ }^{32}$.

Con todo, me parece que nuestra jurisprudencia asume que la posición institucional en la que se inserta el juez tiene una trascendencia fundamental respecto a la función de aplicar el Derecho al caso concreto ${ }^{33}$. Nuestros jueces se sienten autorizados para suplir y corregir las actuaciones erróneas, negligentes e insuficientes de los litigantes en la invocación del Derecho, misión que en otro orden de actuaciones procesales, en especial

${ }^{32}$ Legislaciones modernas han tenido que adaptar sus instituciones procesales para permitir al juez fundar sus sentencias en argumentaciones o puntos de vista jurídicos no propuestas por las partes. Así ha sucedido, por ejemplo, en Alemania con la modificación del Art. $139 \mathrm{~N}^{\circ} 2$ de la Ordenanza Procesal, que indica: "El tribunal, salvo que se trate de una petición accesoria, no puede dictar sentencia con fundamento en un punto de vista claramente ignorado o considerado irrelevante por una parte sin antes realizar a los litigantes la oportuna advertencia o indicación y ofrecerles la oportunidad de realizar las alegaciones que crea convenientes. Lo mismo será de aplicación cuando el tribunal valore un punto de vista de forma diferente que ambas partes”. Casi de idéntico tenor es el Art. 182 de la Ordenanza Procesal Austriaca que, de igual manera, estima necesario someter a consideración de las partes el punto de vista novedoso que quiere introducir el juez al momento de decidir. Mucho más palmaria es la legislación francesa, que en su artículo 16 inciso $3^{\circ}$ expresa que el juez "no podrá fundar su decisión en fundamentos de derecho apreciados de oficio sin haber invitado previamente a las partes a exponer sus observaciones".

${ }^{33}$ El carácter institucional del juez como fundamento de su libertad en la aplicación del derecho, se basa en la idea de que el derecho es un sistema normativo institucionalizado. Las normas jurídicas, como motivadoras de las conductas de los seres humanos, tienen como rasgo esencial que las diferencia de las otras normas de conductas (morales, éticas, religiosas, etc.) que están provistas de una sanción que ha sido creada por ciertas instituciones para ser aplicadas por instituciones. Vid., Moreso, J. y Vilajosana, J., Introducción a la teoría del derecho, Marcial Pons, Madrid, 2004, pp. 23 y 24. 
en la alegación de los hechos y la prueba, se han negado soterradamente a efectuar ${ }^{34}$. Es más, hay varias sentencias que permiten al juez controlar la procedencia de la acción deducida en todos sus presupuestos, aun en situaciones donde las partes han guardado silencio o estado de acuerdo.

Esta diversa postura frente a los hechos y al Derecho tiene su explicación en la profunda convicción de que a los jueces no les corresponde otra misión que la de aplicar las normas jurídicas al caso sometido a su decisión, tanto porque se les presume conocedores del Derecho como porque sus decisiones son legítimas en la medida que se ajusten a la ley, más allá si la alegación jurídica de la parte haya sido o no correcta. La única exigencia reconocible para el órgano adjudicador sería que su sentencia se base en el Derecho y nada más que en el Derecho. De ahí que sea común reducir la participación del juez en el desarrollo dinámico de la jurisdicción a los aspectos netamente formales sin conferirle ningún tipo de potestad para aportar prueba. Y al contrario existe la tendencia de darle un poder amplio para enmendar todo tipo de error que haya cometido la defensa al momento de precisar los materiales jurídicos que fundamentan una pretensión ${ }^{35}$.

En este sentido, es curioso observar cómo la jurisprudencia para legitimar y justificar la utilización de un amplio poder en la aplicación de los materiales jurídicos y corregir la negligencia, torpeza y error de las partes, tenga que efectuar una verdadera autorreflexión acerca de cuál es la función y responsabilidad del juez en el ordenamiento jurídico ${ }^{36}$. Reflexión que no ha efectuado cuando se trata de errores en la alegación de un hecho o la aportación de prueba.

${ }^{34}$ Si bien no hay sentencias que así lo dispongan expresamente, es posible observar que la idea de complementariedad que se le ha venido dando a las medidas para mejor resolver como modalidad del poder probatorio del juez, va por el camino de entender que los tribunales no están llamados a suplir la actividad probatoria de las partes. Nuestros jueces han sido particularmente reacios en decretar una medida probatoria cuando no hay prueba destinada a acreditar el hecho. Por el contrario, fuera de todo texto legal, han ido recortando la potestad judicial exigiendo un principio de prueba sobre un hecho que sea necesario complementar o adicionar. Así, la Corte de Apelaciones de Santiago, en sentencia de 13 de junio de 1952, reconoció que "las medidas para mejor resolver sólo pueden decretarse con el fin de complementar o adicionar la prueba rendida por las partes; prueba que sólo puede versar sobre los hechos calificados por el tribunal como susceptibles de ser probados en la resolución correspondiente”. C. Santiago, 13 de junio de 1953, R.D.J., t. 49, sec. $2^{\text {a }}$, p. 144. Otro fallo de la Corte Suprema, de 31 de agosto de 1970, señala que "las medidas para mejor resolver que autoriza este precepto -se refiere al Art. 159 del CPC-constituyen una facultad que pueden usar los tribunales cuando en autos aparezca un antecedente serio que permita esclarecer por medio de algunas de estas medidas el asunto sometido a su decisión”. C. Suprema, 31 de agosto de 1970, R.D.J., t. 67, sec. $1^{\text {a }}$, p. 366. Así también: C. Valdivia, 12 de julio de 1912, GJ, 1912, t. I, No 601, p. 991.

35 Especialmente sincero es un fallo de la Corte Suprema donde reconoció al tribunal una potestad amplia para aplicar las reglas legales atinentes al caso en la medida que la falta de una defensa adecuada en este aspecto podría traer como consecuencia la pérdida o negación de un derecho indiscutible. C. Suprema, 11 de agosto de 1965, R.D.J., t. 62, sec. $1^{\text {a }}$, p. 272.

${ }^{36}$ Representativo de lo dicho es un fallo de la Corte de Concepción donde reconociendo que los actores fundaron equivocadamente su pretensión en las normas de la responsabilidad aquiliana, señala que a las partes sólo le corresponde introducir los hechos al proceso y probarlos, mientras que al juez la determinación del derecho aplicable a tales hechos. Agrega este mismo fallo que "las apreciaciones y razones jurídicas que plantean las partes en apoyo de sus tesis no obligan al juez, quien es enteramente libre para acogerlas o no, 
Sin embargo, entiendo que lo que está detrás de esa autorreflexión son criterios de eficacia del proceso. En efecto, cada vez que el tribunal efectúa una reflexión en torno a su posición frente a la norma jurídica es porque el demandante ha errado en la fundamentación de supretensión, de manera que de no reconocerse una libertad en ese ámbito esa pretensión no tendría otro camino que la de ser desechada. Desde luego que esta solución hace del proceso un instrumento altamente ineficaz e ineficiente. Ineficaz, puesto que cuando el derecho subjetivo realmente existe y se reclama una tutela, éste queda sin protección frente a la imperfecta alegación de las normas jurídicas, y el proceso se muestra inútil e infructífero para cumplir su función esencial. Ineficiente, en la medida que tanto las partes como el Estado invierten importantes recursos - por definición escasos- para llevar adelante un largo proceso sin que se arribe a una solución adecuada.

Así entonces no cabe duda que la posibilidad de enmendar los yerros en que han incurrido las partes al momento de invocar el Derecho aplicable permite cumplir los objetivos que institucionalmente se han diseñado para el proceso civil, esto es, ser un mecanismo de tutela y protección de los derechos subjetivos e intereses de los ciudadanos.

\section{2. ¿Es cierta la separación propuesta por la jurisprudencia entre cuestiones de becho y de derecho?}

Uno de los tópicos donde es posible efectuar una crítica al razonamiento judicial es en la estricta separación que han reconocido entre las cuestiones jurídicas y las cuestiones fácticas del caso, como si se tratara de fenómenos fácilmente separables y diametralmente opuestos. Este razonamiento jurisprudencial puede tener dos explicaciones: en primer lugar, entender que aún nuestros jueces creen que el modelo propio de adjudicación se aproxima al del silogismo judicial, donde la premisa mayor está conformada por la norma general y abstracta que puede ser libremente escogida por el tribunal, y la premisa menor por el supuesto de hecho que debe ser suministrado por los litigantes. Al juez, en su sentencia, le correspondería subsumir los hechos aportados por las partes en la norma general y abstracta libremente escogida por él, para luego adjudicar la consecuencia jurídica establecida en la norma ${ }^{37}$. Este modelo de adjudicación judicial permite, sin mayor inconveniente, separar y distribuir las tareas procesales de aportar los hechos (premisa menor) y el Derecho (premisa mayor), legitimando una posición activa del tribunal en orden a la búsqueda de la norma general que cuadre con los hechos alegados por los litigantes.

Una segunda explicación que se puede dar para entender este razonamiento judicial proviene de la vigencia y entendimiento del recurso de casación en el fondo, que

pues, de acuerdo a un antiguo aforismo jurídico, 'iura novit curia', el juez conoce el derecho”. C. Concepción, 10 de agosto de 2000, Rol No 1977-1999.

${ }^{37}$ De esto mucho se ha dicho en el ámbito de la filosofía y teoría del derecho, cuestión de la cual no me haré cargo por sobrepasar los modestos límites de este trabajo. Vid., para una panorámica general: De Asís Roig, R., Jueces y normas. La decisión judicial desde el Ordenamiento, Marcial Pons, Madrid, 1995, pp. 97 y siguientes. 
ha supuesto un poder para conocer únicamente las cuestiones jurídicas del caso, con exclusión de los hechos que quedan al margen de la casación ${ }^{38}$. Esta distinción está afianzada en la naturaleza jurídica de la casación como recurso destinado a controlar las cuestiones estrictamente jurídicas, y ha fortalecido esa separación. Así nuestra Corte Suprema tendría competencia para efectuar la calificación jurídica de los hechos o actos que previamente han sido establecidos por los jueces de la instancia ${ }^{39}$, fomentando, de esta forma, el poder de los jueces para administrar las normas aplicables.

Desde luego que esta visión no es correcta ni desde la pura teoría ni desde la realidad práctica, o al menos de aquello que frecuentemente se ve en los tribunales. La teoría enseña que es prácticamente imposible separar las cuestiones de hecho y de derecho como si se tratara de realidades sin relación o conexión. Los datos fácticos son introducidos al proceso mediante actos de alegación que pretenden vincular al juez para tenerlos como base de una determinada consecuencia jurídica ${ }^{40}$. No es efectivo que la parte no se posicione frente a la norma jurídica que estima aplicable para seleccionar los elementos de hecho que debe introducir para obtener el efecto jurídico deseado; la alegación de un determinado acontecimiento no es un simple elemento dialéctico destinado a convencer al juez para que dicte una sentencia favorable, sino es un elemento esencial para identificar la razón por la cual se pide una determinada tutela y un bien de la vida ${ }^{41}$. El supuesto fáctico abstracto y general que viene previsto en la norma jurídica constituye entonces el criterio de selección y relevancia de los hechos introducidos al proceso. De esta forma, si hay un cambio en la norma que se estima aplicable también podría haber una modificación en el criterio de la relevancia con que el justiciable introduce el hecho. Esto implica que del conjunto de enunciados fácticos que contiene una demanda sólo algunos juegan un rol constitutivo de la pretensión, esto es, aquellos que cuadran con los presupuestos de las normas que otorgan el efecto jurídico pretendido ${ }^{42}$.

38 Como afirma Guasch, S., El hecho y el derecho en la casación civil, J.M. Bosch, Barcelona, 1998, p. 179, "la escisión teórica entre juicio el juicio de derecho y el juicio de hecho ha servido para que el poder cognoscitivo de la casación quedara al margen del hecho con el fundamento de la estructura práctica del silogismo judicial".

39 Así se ha dicho, entre otras: C. Suprema, 15 de abril de 1915, R.D.J., t. 13, sec. 1a, p. 33; C. Suprema, 8 de abril de 1919, R.D.J., t. 17, sec. $1^{\text {a }}$, p. 19; C. Suprema, 21 de diciembre de 1937, R.D.J., t. 35, sec. $1^{\text {a }}$, p. 292; C. Suprema, 27 de diciembre de 1943, R.D.J., t. 41, sec. $1^{\text {a }}$, p. 516; C. Suprema, 22 de abril de 1946, R.D.J., t. 43, sec. $1^{\text {a }}$, p. 449; C. Suprema, 13 de diciembre de 1946, R.D.J., t. 44, sec. $1^{\text {a }}$, p. 91 y C. Suprema, 30 de julio de 1954 , R.D.J., t. 51, sec. $1^{\text {a }}$, p. 390.

${ }^{40} \mathrm{La}$ alegación de un hecho consiste en la atribución de un valor jurídico determinado a un acontecimiento para producir un efecto jurídico también determinado. Por ejemplo, la alegación del dominio del actor y la posesión del demandado para pretender la restitución de una propiedad. Esta definición la extraigo de: Buoncristiani, D., L' allegazione dei fatti nel processo civile. Profili sistematici, Giappichelli Editore, Torino, 2001, p. 26.

${ }^{41}$ Vid., Gómez, E., Derecho Procesal Civil, Parte General, El Proceso Declarativo, Tomo I, Artes Gráficas y Ediciones, Madrid, 1979, p. 186.

42 Taruffo, M., op. cit., pp. 91 a 97. Tal como lo explica Taruffo, la demostración de los hechos en el proceso no está destinada a satisfacer exigencias de conocimiento en estado puro, sino para la resolución de controversias que versan sobre la existencia de derechos. Por ende, el proceso está dirigido a la demostración de un hecho en cuanto es presupuesto de la aplicación de la norma jurídica. Los hechos son identificados e 
Conforme a este razonamiento no es tan preciso que las partes hayan introducido los hechos sin mirar la norma aplicable y, por el contrario, tampoco es preciso que el juez pueda aplicar libremente el Derecho sin tener en cuenta que esos datos han sido introducidos en base a criterios jurídicos. En realidad los hechos y el derecho se limitan recíprocamente. La norma jurídica es la que identifica los hechos relevantes para conseguir el efecto jurídico deseado; por ende, los hechos siempre marcarán un límite inmanente al Derecho aplicable.

Bajo esta perspectiva, aquella distribución de roles tan acentuada en los diferentes fallos debe necesariamente relativizarse, y no sólo en la forma en que se están adoptando las decisiones jurisdiccionales sino también en el discurso con que el órgano judicial fundamenta su participación en la aplicación del Derecho. Me parece razonable que la jurisprudencia siga reconociéndose poseedora de un poder amplio en orden a la utilización de los materiales jurídicos cuando éstos no han sido invocados, o su invocación es errónea e imperfecta, pero a su vez, es necesario que abandone esa suerte de "posición superior" del órgano frente a la norma jurídica. En cierta forma, si la petición concreta y los hechos son alegados e introducidos por las partes, son ellas también las que han definido qué norma puede o no ser aplicada.

Por otra parte, esta separación también es errada desde el plano práctico. Los litigantes, por lo general, realizan un intenso trabajo en la búsqueda de los materiales jurídicos que regulan su relación jurídica-material. Si bien no le es exigible una completa precisión en la invocación del Derecho tampoco es exacto decir que asumen la actividad jurídica argumentativa con indiferencia. La realidad muestra que los abogados intentan traducir a términos jurídicos los planteamientos fácticos contenidos en la demanda, y que la investigación e invocación de "alguna institución jurídica" es esencial para justificar el beneficio jurídico perseguido y, sobre todo, para el éxito de sus defensas. Tan intenso es el trabajo que realizan las partes que muchas veces los hechos aparecen entremezclados con las cuestiones jurídicas, de manera que la distinción de dos ámbitos de adjudicación es más bien aparente.

\section{3. ¿Dónde queda el derecho de defensa?}

Lo dicho hasta el momento acerca del principio del iura novit curia podría llevarnos a concluir que los poderes del tribunal son ilimitados en relación a la aplicación del Derecho. Sin embargo, si bien los jueces pueden controlar libremente las normas jurídicas aplicables, esta actividad está limitada por la vigencia de los derechos de los justiciables $y$, en especial, el derecho de defensa de la parte demandada.

introducidos por los ciudadanos en base a criterios jurídicos que sirven para seleccionarlos, y esos criterios son las normas jurídicas. Con esto es claro que hecho y derecho no son realidades separables o sin implicación; más bien en el proceso civil los hechos son identificados, seleccionados e individualizados en base a una norma de derecho que sirve de criterio de relevancia. Así también opina: Guasch, S., op. cit., p. 194 y Garcimartín, R., El objeto de la prueba en el Proceso Civil, Cedecs Editorial, Barcelona, 1997, p. 53. 
Cuando el litigio se desarrolla y resuelve alrededor de las alegaciones jurídicas y calificaciones formuladas por las partes en el curso del proceso, no hay conflicto de ningún tipo, y ahí es posible afirmar que el juez tiene una libertad absoluta para la definición y aplicación de los materiales jurídicos. Pero, como muy bien observa Ormazabal, la desvinculación del juez a los puntos de vista jurídicos sostenidos por las partes en el debate puede ocasionar reparos en relación al derecho de defensa. Estos reparos se centran en lo novedoso y sorpresivo de la calificación jurídica en que se sustenta la condena y respecto de la cual el demandado nada ha podido alegar u objetar durante el proceso ${ }^{43}$. Desde luego que nadie puede discutir la validez de la "tercera opinión", puesto que no es más que la aplicación del Derecho al caso concreto, un ejercicio puro de jurisdicción. El problema es determinar cómo se puede hacer valer esta opinión sin negar la contradicción de las partes sobre esta nueva tesis ${ }^{44}$.

Me parece que en el momento actual del Derecho Procesal mirar el reparto de roles bajo la exclusiva lupa de la mayor proximidad del juez al Derecho y de las partes a los hechos y la prueba, es un ejercicio de simplificación no del todo correcto. Desde el punto de vista de los derechos constitucionales es evidente que el ciudadano que recurre a la jurisdicción tiene consagrado una serie de derechos en el orden procesal que forman parte de la cláusula constitucional de "debido proceso". Dentro de esos derechos está el de defensa. En consecuencia, asumo como premisa fundamental que cualquier rol que se le pueda asignar al tribunal en el ámbito que vengo hablando no puede lesionar el derecho de defensa del ciudadano. De ser esto cierto, la libertad del juez para aplicar el derecho al caso concreto no debería ser tan absoluta y la distribución de roles en el proceso civil debería encontrar un punto de equilibrio entre eficacia y respeto a las garantías procesales del justiciable.

En un sistema ideal el juez debería tener la posibilidad de provocar de oficio el debate preventivo sobre todas las cuestiones de hecho y de Derecho que sean determinantes para la resolución de la controversia. De esta forma, las partes desde sus parciales puntos de vista pueden influir en el contenido de la decisión, ayudando a formar la convicción del juez en los aspectos jurídicos relevantes del litigio ${ }^{45}$. Si el juez se aparta del material involucrado en el desarrollo del contradictorio y sorprende con una posición jurídica no discutida ni tratada en el proceso, coarta el derecho de defensa al decidir sin dar la posibilidad a las partes de efectuar sus alegaciones jurídicas ${ }^{46}$.

\footnotetext{
${ }^{43}$ Cfr., Ormazabal, G., Iura novit curia. La vinculación del juez a la calificación jurídica de la demanda, Marcial Pons, Madrid, 2007, p. 106.

${ }^{44}$ Vid., Montero, J., Derecho Jurisdiccional I, con Gómez, J., Montón, A., y Barona, S., Tirant Lo Blanch, Valencia, 2001, p. 323.

45 Ya lo afirmaba Couture cuando decía que la defensa era en sí mismo un "acto de persuasión dialéctica” que permite crear el convencimiento del magistrado hacia una resolución favorable. Cfr. Couture, E., "Las garantías constitucionales del proceso civil" en Estudios de Derecho Procesal Civil, Tomo I, LexisNexis, Buenos Aires, 2003, p. 47.

${ }^{46} \mathrm{Si}$ la indefensión consiste "en no sufrir en el seno del proceso una privación o limitación de las posibilidades esenciales del derecho de defensa -alegación y/o prueba- (...)”, entonces no cabe duda que una sentencia que resuelve un conflicto sin escuchar a las partes produce indefensión. Vid., Díez-Picazo, I.,
} 
Esta complicación podría verificarse en dos casos. Primero cuando el juez cambia o modifica la calificación jurídica contenida en la demanda no habiendo contradicción previa entre las partes. Por ejemplo, cuando el actor plantea una demanda por responsabilidad contractual y el juez, en la sentencia, acoge la pretensión con fundamento en la responsabilidad extracontractual. No cabe duda que esa modificación en tanto no altere el criterio de relevancia con que se introducen los hechos es perfectamente válida. En realidad el juez corrige una imperfecta invocación del Derecho. Sin embargo, si no ha existido discusión acerca de la naturaleza de la responsabilidad dicho fallo podría catalogarse de incongruente. Lo decidido por el juez no es congruente con lo debatido y discutido en el proceso.

El segundo caso donde podría haber una lesión al derecho de defensa se produce cuando el juez se pronuncia sobre algunos de los extremos de la pretensión donde no existió contradicción previa. Por ejemplo, ninguna de las partes discute la existencia de la mera tolerancia en un juicio de precario, pero el juez termina desestimando la demanda por considerar que no concurren dicho presupuesto.

Cuando el ordenamiento impide a las partes discutir y reconsiderar los puntos de vista jurídicos iniciales el respeto por la contradicción es útil como impedimento para reconocer la libertad del juez en la aplicación del Derecho. Al contrario, si se da la posibilidad a los litigantes de discutir la tercera tesis o la modificación de la calificación jurídica de los hechos que pretende hacer el juez, entonces no habría inconveniente en reconocer un poder amplio del órgano en la utilización de los materiales jurídicos ${ }^{47}$.

Ahora bien, la jurisprudencia nacional al momento de reconocerse un poder para llenar de contenido jurídico a una pretensión no se ha planteado si ese poder puede vulnerar el derecho de defensa del litigante sorprendido con el punto de vista jurídico no debatido. En cierta forma la jurisprudencia ha ignorado completamente este problema en su real magnitud y ha entendido que sobre aquello que le pertenece queda sustraído de la contradicción de las partes. Nuestros jueces siguen sintiéndose autorizados para aplicar el Derecho a la situación concreta sin necesidad de someter a discusión su propuesta jurídica. De ahí que sea común encontrar soluciones que jamás han sido sometidas al escrutinio de las partes y que se verifican únicamente en la sentencia definitiva ${ }^{48}$.

Borrajo, I., y Fernández, G., El derecho a la tutela judicial y el recurso de amparo. Una reflexión sobre la jurisprudencia constitucional. Civitas, Madrid, 1995, p. 100.

47 Esta fue la propuesta planteada por algunos autores españoles a la LEC 1/2000. Se estimaba por algunos que la real preocupación del principio iura novit curia no venía dado en su alcance -el autor supone que el juez debe ser libre para aplicar el derecho, pudiendo cambiar la calificación jurídica contenida en la demanda- sino más bien la forma en que debe procederse cuando el juez pretende dar a los hechos una calificación jurídica distinta a la expuesta en la pretensión. Vid., Garnica, J., "El principio iura novit curia y la determinación del objeto del proceso en el Proyecto de reforma de la Ley de Enjuiciamiento Civil", en La Ley, tomo I, 1999, pp. 1714 y 1716.

${ }^{48}$ Un fallo de la Corte de Apelaciones de Santiago tiene especial cuidado en señalar que, en el caso concreto, la aplicación de normas jurídicas diversas a las invocadas, y la modificación de la calificación jurídica de la demanda no había producido indefensión a la parte demandada desde que los hechos -en principio irrelevantes- que sirvieron para modificar la calificación quedaron asentados en el auto de prueba. C. Santiago, 10 de julio de 2008, Rol No 4594-2007. Esta sentencia es incorrecta, puesto que acá tan sólo 


\section{Propuesta de interpretación: artículos 160 y 768 Nº 4 DEL CPC COMO EXIGENCIAS DE CONGRUENCIA}

Mi propuesta de interpretación recoge las limitaciones que actualmente contiene el CPC en orden a la posibilidad de articular un contradictorio promovido oficiosamente por el tribunal. Es incuestionable que el actual CPC no dispone ningún trámite o momento procesal para que el juez pueda requerir de las partes una discusión previa acerca de los puntos jurídicos más relevantes de la controversia ${ }^{49}$. Por ende, no queda otra opción que aceptar la legitimidad de las decisiones judiciales que se pronuncian sobre extremos de una pretensión que no han sido previamente discutidas por los litigantes. Así, por ejemplo, si entre las partes no ha existido controversia acerca de la mera tolerancia del demandado en un juicio de precario, el juez puede rechazar la demanda cuando considere como jurídicamente inadmisible la situación que se invoca como tal. A menos que se promueva una reforma legislativa destinada a hacer factible esa posibilidad no queda otro camino que aceptar estas decisiones jurisdiccionales. En cierta medida este poder es consustancial al ejercicio de la jurisdicción y la falta de contradicción previa no puede ser motivo para impedir que el juez adopte su decisión fundada en el ordenamiento jurídico.

Válida me parece también la sentencia que decide los términos del debate jurídico, aun cuando pueda modificar la calificación efectuada. Por ejemplo, el demandado sustenta su pretensión en las normas de la responsabilidad contractual y el tribunal acoge la pretensión bajo las normas de la responsabilidad extracontractual. Aquí el actor equivoca el camino jurídico e invoca normas que no son aplicables a los hechos contenidos en la pretensión. Pero si entre las partes media contradicción sobre esos extremos, entonces no cabe duda que la decisión adoptada es plenamente legítima.

Por el contrario, me parece que es posible recortar la libertad del juez para aplicar el Derecho cuando no ha existido debate sobre los puntos jurídicos. El juez no puede acoger una pretensión - pero sí rechazarla- en base a una calificación diversa. Si así lo hiciera estaría infringiendo el derecho de defensa y siendo incongruente ${ }^{50}$. Es cierto

se evitó la indefensión desde el punto de vista fáctico, pero no del jurídico. Que las partes hayan podido probar los hechos objeto de la nueva calificación no es más que el presupuesto necesario para la aplicación de la norma. Lo objetable es la omisión en la posibilidad de dar argumentos jurídicos.

${ }^{49}$ Una sentencia de la Corte de Apelaciones de Santiago, de 8 de julio de 1941, aceptó que en el escrito de réplica se modificara la calificación jurídica formulada por el actor en la demanda. C. Santiago, 8 de julio de 1941 , R.D.J., t. 39, sec. $2^{a}$, p. 41. Esta posibilidad abriría la puerta para que sean las partes las llamadas a modificar una determinada calificación, y discutir sobre la misma mientras se mantengan inalterados los hechos expuestos en la demanda. Sin embargo, el juez sigue estando "atado de manos" para proponer este cambio en el punto de vista jurídico.

${ }^{50}$ Hay que tener especial cuidado con la vigencia de la contradicción en esta materia. La idea de contradicción está en la base de la construcción teórica del proceso, y se acuña en la clásica definición "audiatur el altera pars", que establece que los litigantes tienen el derecho a ser escuchados en toda actuación que afecte su posición en el proceso. Esto llevado al ámbito que nos interesa significa que cualquier decisión que se adopte y que sea favorable para el demandante debe producirse habiendo dado la posibilidad al demandado de contradecir los puntos de esa decisión. 
que esta interpretación choca con lo sustentado por parte de la jurisprudencia que ha entendido que la ultra petita (Art. $768 \mathrm{~N}^{\circ} 4$ del CPC) se refiere únicamente a los casos donde el juez se pronuncia de oficio sobre la procedencia de pretensiones no deducidas o altera el objeto y causa de pedir ${ }^{51}$.

Sin embargo, hay algunos fallos que tienden, tímidamente, a extender la ultra petita a situaciones donde el juez resolvió fuera de los términos en que se situó el debate. Así parece demostrarlo, por ejemplo, una sentencia de la Corte Suprema de 10 de noviembre de 2005, que rechaza una demanda por haberse fundado en un preciso estatuto jurídico que no resultaba aplicable y que condicionó las alegaciones y defensas que pudo oponer el demandado en el juicio ${ }^{52}$. A esta sentencia puede añadirse otra de 8 de junio de 1961, que señaló que "el precepto del artículo 160 del Código de Procedimiento Civil, en orden a establecer que toda sentencia debe conformarse con el mérito del proceso, si no es debidamente cumplido por el sentenciador, da origen a un recurso de casación en la forma por la causal prevista en el $\mathrm{N}^{\circ} 4$ del artículo 768 del citado cuerpo legal" 53 . Por último, otros fallos de nuestro máximo tribunal han dicho de modo expreso que "la libertad del juez para interpretar y aplicar el derecho, queda delimitada por el principio de congruencia, el cual le otorga el marco de su contenido", siendo la congruencia la forma de "vincular a las partes y al juez al debate" 54 .

Una interpretación armónica de los artículos 160 y 768 Nº 4 del CPC podría abrir el camino para dar cabida en nuestro proceso civil a una exigencia de congruencia de las resoluciones judiciales. Para este efecto propongo efectuar una lectura laxa de estas

51 Así de clara fue la Corte Suprema, que en fallo de 6 de agosto de 1992, precisó que la ultra petita "en su aspecto de haberse extendido la sentencia a puntos no sometidos a decisión del Tribunal, debiendo tenerse presente, en primer lugar, que el vicio se produce en lo decisorio cuando se altera el contenido de las acciones y excepciones planteada por las partes y, en segundo lugar, que esta alteración se produzca porque se cambia o modifica el objeto o causa de pedir en tales acciones o excepciones". C. Suprema, 6 de agosto de 1992, Rol N 16.065 . Otro fallo de la Corte de Santiago, ratificado por la Corte Suprema, acepta que el tribunal calificara la demanda de "nulidad por error esencial" cuando había sido fundamentada como "falta de objeto", estimando que la causa de pedir era idéntica, no incurriendo, por tanto, en ultra petita. C. Santiago, 4 de septiembre de 1998, Rol No 2135-2009, y C. Suprema, 5 de diciembre de 2006, Rol No 1248-2004.

52 C. Suprema, 10 de noviembre de 2005, Rol No 4909-2003. Otra sentencia de la Corte Suprema que parece vincular la decisión del juez al debate es la 2 de octubre de 1934 que precisó: "procede anular de oficio la sentencia que se pronuncia en mérito de fundamentos ajenos en absoluto a los invocados por las partes, porque extendiéndose a un punto extraño a los sometidos a la decisión de los jueces, falla ultra petita”. C. Suprema, 2 de octubre de 1934, R.D.J., t. 32, $2^{\circ}$ parte, p. 362.

53 C. Suprema, 8 de junio de 1961, R.D.J., t. 58, sec. $1^{\text {a }}$, p. 153 , y C. Suprema, 3 de diciembre de 1915, R.D.J., t. 13 , sec. $1^{\text {a }}$, p. 359.

${ }^{54}$ C. Suprema, 19 de octubre de 2009, Rol No 5159-2008; C. Suprema, 7 de julio de 2009, Rol $\mathrm{N}^{\circ}$ 2863-2008, y C. Suprema, 11 de mayo de 2009, Rol No 2313-2008. Estas sentencias son un verdadero compendio de lo dicho hasta el momento por la Corte Suprema en materia de ultra petita. Sin embargo, son particularmente confusas, puesto que de su lectura no queda claro si nuestro máximo tribunal entiende que la congruencia de las resoluciones hay que vincularlas únicamente al respeto de la causa de pedir y el objeto pedido, dándole plena libertad al juez para aplicar el Derecho, o también a la coherencia con el debate que ha precedido a la decisión jurisdiccional. En este último caso, el juez no podría salir de los términos de la discusión para acoger una pretensión. 
disposiciones con la finalidad de superar su típico entendimiento como ultra petita. Esta lectura consistiría en admitir que la prohibición de no extender la sentencia a "puntos no sometidos a la decisión del tribunal" está haciendo alusión a la imposibilidad de que el juez se pronuncie acogiendo una pretensión en base a aspectos no debatidos ${ }^{55}$. Esta conclusión, desde luego, genera algunas consecuencias bastante significativas en la libertad del juez en la aplicación de los materiales jurídicos. En primer lugar, no puede sin previo debate modificar la calificación jurídica propuesta en la demanda para acoger una pretensión. Si no ha existido un debate acerca de la calificación jurídica de los hechos no puede el juez modificarla para acoger la pretensión. En segundo lugar, puede rechazar una pretensión proponiendo una nueva calificación jurídica diversa a la discutida en el pleito. De esta manera se respeta íntegramente el derecho de defensa

\section{UNA REFLEXIÓN DE LEGE FERENDA. LA CONTRADICCIÓN COMO ELEMENTO LEGITIMADOR DE LA INVESTIGACIÓN Y APLICACIÓN DE LA NORMA JURÍDICA POR PARTE DEL JUEZ}

En un sistema eficiente de adjudicación judicial el juez debería tener la libertad tanto para aplicar la norma jurídica al caso concreto como para investigarla cuando estime que la calificación propuesta no es correcta. En este último caso, la nueva calificación debería ser sometida a la contradicción de las partes, de manera de legitimar, de esa forma, la decisión que se adopte. Bajo este perfil el juez estaría autorizado para acoger una pretensión en base a una calificación diversa a la propuesta por las partes o a la originalmente discutida. Pero es claro que esta dinámica no se cumple en el actual procedimiento civil.

Por ende, es dable entender que el juez pueda únicamente comprobar si los materiales jurídicos invocados por los litigantes para la tutela de una situación jurídica son correctos, cuestión que le permitiría recorrer todos los extremos de una acción o excepción aun cuando no hayan sido discutidos por las partes. Por el contrario, parece cuestionable que pueda reconocerse un poder al juez para investigar y buscar la institución jurídica aplicable y tomarla de base para acoger una pretensión, puesto que no tiene la posibilidad de someterla a la contradicción de las partes ${ }^{56}$.

55 Es curioso observar que la misma jurisprudencia que se siente libre para aplicar el Derecho al caso concreto sin necesidad de ceñirse a los términos del debate, exija a los litigantes fundar el recurso de casación en el fondo en normas jurídicas que hayan sido materia del juicio, o que hayan sido promovidas y discutidas en él. Así, entre otros: C. Suprema, 21 de abril de 1954, R.D.J, t. 51, sec. 1a, p. 83; C. Suprema, 10 de marzo de 1954, R.D.J., t. 51, sec. $1^{\text {a }}$, p. 57; C. Suprema, 8 de junio de 1945, R.D.J., t. 43, sec. $1^{\text {a }}$, p. 18; C. Suprema, 27 de octubre de 1943 , t. 41, sec. $1^{\text {a }}$, p. 289 y C. Suprema, 9 de diciembre de 1942 , R.D.J, t. 40, sec. $1^{\text {a }}$, p. 342. Hay ciertamente un doble discurso: para el juez el debate es irrelevante en la aplicación del Derecho. En cambio, para los litigantes, el debate que se haya producido sobre los aspectos jurídicos los vincula al momento de formalizar el recurso de casación en el fondo.

${ }^{56}$ La distinción entre el poder de aplicar la norma jurídica y de buscar la norma para proceder a aplicarla puede verse en: Millar, C., La incongruencia civil, Editorial Tecnos, Madrid, 1983, p. 97. Con todo, el 
Entiendo que esta última interpretación puede dar lugar a algunas inequidades e injusticias, además de hacer del proceso una herramienta ineficiente y que conduce a resultados ineficaces. Si no le reconocemos al juez un poder para investigar y aplicar la norma jurídica correcta podrían presentarse situaciones altamente injustas, lo que ocurriría cuando un juez rechaza una pretensión bajo un determinado fundamento jurídico, y luego cuando se vuelve a proponer en base a un fundamento jurídico diverso (seguramente invocando aquel que señala la sentencia desestimatoria como correcto), otro juez, también la rechaza, ya sea no estar de acuerdo con los fundamentos jurídicos, o peor aún, por considerar que hay cosa juzgada.

Si pensamos al proceso civil como una herramienta eficiente que se destina a dar tutela a los ciudadanos y que debe conciliar el interés de éstos con los del Estado, me parece indispensable plantear la necesidad de incorporar en el CPC actual o en el Proyecto de Código Procesal Civil algún momento del proceso para que el juez pueda someter al escrutinio de las partes la nueva calificación jurídica con la que pretende resolver la controversia.

Esta solución viene siendo reconocida y propugnada en gran parte de los ordenamientos modernos, por ser una exacta conjugación entre el respeto por las garantías procesales y eficacia del proceso.

\section{CONCLUSIONES}

En el ámbito del proceso civil la distribución de roles ha estado cimentada sobre concepciones ideológicas acerca de la función del proceso. Sin embargo, cuando se trata de analizar los poderes que les corresponde a los jueces en el ámbito de la utilización de los materiales jurídicos, esa discusión pasa a un segundo plano, y el discurso suele estructurarse en dogmas difícilmente cuestionables; uno de ellos, sin dudar, es aquel que ve en el juez un conocedor del sistema normativo. Bajo esta perspectiva es frecuente reconocer una libertad indiscriminada para que el órgano judicial aplique el Derecho al caso concreto, con la única limitación de ajustarse íntegramente a los hechos alegados y no conceder un beneficio jurídico diferente al pedido. A las partes se les reservaría la introducción de los hechos y la prueba.

Esta repartición de tareas tiene un fuerte correlato en la jurisprudencia nacional. Nuestros tribunales han declarado expresamente que les corresponde una función activa en la aplicación del Derecho y, al contrario, que carecen de toda iniciativa en la introducción de los hechos. Además han extraído otras consecuencias que derivan de esta libertad, como la posibilidad de enmendar los errores en las citas legales, suplir la falta de cita legal, modificar la calificación jurídica de los hechos, corregir la imperfecta o errónea argumentación jurídica, etc.

mismo autor reconoce que la doctrina viene predicando hace un par de años la necesidad de advertir a las partes la divergencia sobre el punto de vista jurídico, con el fin de evitar no sólo sorpresas sino también la posibilidad modificar la defensa cuando hay una mutación jurídica de la pretensión. 
Sin embargo, en esta materia sigue siendo ajena al discurso judicial la operatividad de los derechos del justiciable, en especial, del derecho de defensa del demandado. La aplicación oficiosa del Derecho al momento de dictar sentencia merece severos reparos desde la óptica del derecho de defensa, por cuanto los litigantes no han tenido la oportunidad de discutir la nueva propuesta jurídica. En ese sentido, se hace indispensable crear los mecanismos necesarios para que nuestro actual procedimiento civil permita a las partes discutir los puntos jurídicos no debatidos. Esta posibilidad al no encontrarse reconocida en el proceso actual debe ser suplida modificando la regla en cuanto a la aplicación del Derecho. Esto implica que el juez sigue estando facultado para utilizar todos los materiales jurídicos del caso, pero no para acoger una pretensión. Sólo en la medida que la nueva calificación pueda ser objeto de debate es posible aceptar un poder ilimitado del órgano judicial.

\section{BIBLIOGRAFÍA}

Buoncristiani, D., L' allegazione dei fatti nel processo civile. Profili sistematici, Giappichelli Editore, Torino, 2001.

Couture, E., "Las garantías constitucionales del proceso civil", en Estudios de Derecho Procesal Civil, Tomo I, Lexis Nexis, Buenos Aires, 2003, pp. 19 a 67.

Damaska, M., Las caras de la justicia y del poder del Estado. Análisis comparado del proceso legal, Editorial Jurídica de Chile, Santiago, 2000.

De Asís Roig, R., Jueces y normas. La decisión judicial desde el Ordenamiento, Marcial Pons, Madrid, 1995.

De la Oliva Santos, A., El objeto del proceso y la cosa juzgada en el proceso civil, Civitas, Madrid, 2005.

Díez-Picazo, I., Borrajo, I., y Fernández, G., El derecho a la tutela judicial y el recurso de amparo. Una reflexión sobre la jurisprudencia constitucional. Civitas, Madrid, 1995.

EzQuiaga, F., Iura novit curia y aplicación judicial del derecho, Editorial Lex Nova, Valladolid, 2000.

Garcimartín, R., El objeto de la prueba en el Proceso Civil, Cedecs Editorial, Barcelona, 1997.

GARnICA, J., "El principio iura novit curia y la determinación del objeto del proceso en el Proyecto de reforma de la Ley de Enjuiciamiento Civil" en La Ley, tomo I, 1999, pp. 1713 a 1716.

Gómez, E., Derecho Procesal Civil, Parte General, El Proceso Declarativo, Tomo I, Artes Gráficas y Ediciones, Madrid, 1979.

GuAsCH, S., El hecho y el derecho en la casación civil, J.M. Bosch, Barcelona, 1998.

Hunter, I., "¿Tiene el tribunal algún deber en orden al impulso procesal en el actual proceso civil chileno?", en Revista de Derecho Universidad Austral de Chile Tomo XXI, Vol. 1, 2009, pp. 265 a 274.

Millar, C., La incongruencia civil, Editorial Tecnos, Madrid, 1983.

Montero, J., Derecho Jurisdiccional I, con Gómez, J., Montón, A., y Barona, S., Tirant Lo Blanch, Valencia, 2001.

Moreso, J., y Vilajosana, J., Introducción a la teoría del derecho, Marcial Pons, Madrid, 2004.

Ormazabal, G., Iura novit curia. La vinculación del juez a la calificación jurídica de la demanda, Marcial Pons, Madrid, 2007.

Prieto, L., "El cambio del punto de vista jurídico" en Revista de Derecho Procesal, Madrid, 1956. TApia, I., El objeto del proceso. Alegaciones. Sentencia. Cosa juzgada, Editorial La Ley, Madrid, 2000.

TAruffo, M., La prueba de los hechos, Editorial Trotta, Madrid, 2002.

VAllines, E., La preclusión en el proceso civil, Civitas, Madrid, 2004. 
